\title{
A Survey of the DVB-T Spectrum: Opportunities for Cognitive Mobile Users
}

\author{
László Csurgai-Horváth, István Rieger, and József Kertész \\ Department of Broadband Infocommunications and Electromagnetic Theory, Budapest University of Technology and Economics, \\ Egry J. Street 18, Budapest 1111, Hungary
}

Correspondence should be addressed to László Csurgai-Horváth; csurgai@hvt.bme.hu

Received 18 February 2016; Revised 30 May 2016; Accepted 5 July 2016

Academic Editor: Janne Lehtomäki

Copyright (C) 2016 László Csurgai-Horváth et al. This is an open access article distributed under the Creative Commons Attribution License, which permits unrestricted use, distribution, and reproduction in any medium, provided the original work is properly cited.

Cognitive radio (CR) systems are designed to utilize the available radio spectrum in an efficient and intelligent manner. Terrestrial Digital Video Broadcasting (DVB-T) frequency bands are one of the future candidates for cognitive radio applications especially because after digital television transition the TV white spaces (TVWS) became available for radio communication. This paper deals with the survey of the DVB-T spectrum; wideband measurements were performed on mobile platform in order to study the variation of the radio signal power in city area aboard a moving vehicle. The measurement environment was a densely built-in region where the proper DVB-T receiving was guaranteed by three TV transmitters, utilizing three central channel frequencies using 610,746 , and $770 \mathrm{MHz}$. In our paper the methods, the applied antenna, and measurement devices will be presented together with simulated and measured fading statistics. The final result is an estimation of the cognitive DVB-T spectrum utilization opportunity; furthermore a scenario is also proposed for secondary channel usage.

\section{Introduction}

Cognitive radio is an emerging technology to utilize the radio spectrum with high efficiency. The main owners of the spectrum, the primary users (PUs), are not constrained during their operation, while the secondary users (SUs) can operate in the same frequency band if the spectrum is free [1]. It is very important to avoid the degrading of PU's quality of service (QoS) during the cognitive channel usage whereas an acceptable level of service should also be provided for the secondary users. Several technologies should be applied to guarantee these-sometimes contradictoryrequirements [2]. Sensing of the spectrum and detecting the available channels are some of the main tasks of a CR system. The frequency range that can be utilized by the $\mathrm{CR}$ devices depends on the local frequency regulation and therefore it may vary in different countries. In the crowded radio spectrum it is not a simple task to find the appropriate radio bands for cognitive terrestrial devices $[3,4]$. This paper concentrates on the terrestrial television bands and their secondary usage.

In the literature, numerous works are presented about spectrum measurements and on different technologies to support cognitive users in better utilization of the available bandwidth. TV white space is also of a great interest due to the digital TV transition that recently took place in several countries. In the following an overview of this research field will be given in order to put our research into context.

In [5], despite the actual theory that the capacity of the radio spectrum is already achieved, the underutilization of the spectrum is highlighted and the importance of cognitive radio techniques is shown. The paper is focusing on major technologies for opportunistic spectrum access through a hierarchical model approach that adopts the primary and secondary user structure. Spectrum sensing is the key technology to estimating the availability of the licensed spectrum for secondary usage. In [6], the various spectrum occupancy models used in different research campaigns worldwide were studied and compared. The authors evaluate the percentage of the whole spectrum occupied by different services. Longand short-term statistics are presented, showing most of the commercial terrestrial frequency bands (GSM, TV broadcasting, 3G, etc.), utilizing the available spectrum almost below $20-40 \%$. The experiments have been conducted in various locations such as US, Europe, New Zealand, South 
Africa, China, Singapore, and Vietnam. A similar study was performed in Chicago, New York, Washington, DC, and a few rural locations in 2005 between 30 and $3000 \mathrm{MHz}$ [7]. In a large business like Chicago, low spectrum occupancy was observed indicating that a DSS (Dynamic Spectrum Sharing) radio system could access a huge amount of prime spectrum as there are large, unoccupied, contiguous spectrum blocks. The paper [8] collects previous research work carried out worldwide and compares it with spectrum occupancy measurements at the University of Hull, UK. The collected historical measurements are covering also the $30-3000 \mathrm{MHz}$ band and they confirmed the generally low occupancy of the investigated spectrum. The measurements in the UK were performed with a similar hardware configuration to what we also applied during our research work and will be detailed later (spectrum analyser and computer); the frequency range was $80-2700 \mathrm{MHz}$. For DVB-T spectrum measurements in [9], several results can be found especially for occupancy estimations serving as input for outdoor REM (Radio Environment Maps). The measurement setup was similar to the campaign performed in Budapest, but the latter research is focusing also on fade duration statistics and its consequences as it will be later demonstrated. The cellular and the UHF/VHF TV band were studied in [10] for Malaysia and actual spectrum utilization statistics are provided with static measurements. The low duty cycle of the spectrum occupancy was also proved by this study. A comparative spectrum occupancy study was carried out in Barcelona, Spain, and Poznan, Poland [11]. The measurement setups were harmonized to obtain comparable results by concentrating on the problem of the efficient noise floor estimation. As a result, differences have been obtained in the TETRA bands due to the different spectrum allocation regulations in these countries. This study highlights that efficient spectrum detection is always required in order to avoid the congestions due to different local regulatory rules. The change of the UHF TV band spectrum availability due to digital transition in Greece is studied in [12]. They proved that the spectrum availability was significantly increased after the analogue switch-off. Furthermore, the risk of LTE-4G interference to TV services and vice versa is also pointed out according to the spectrum measurements they carried out. A general and detailed discussion on different approaches to spectrum occupancy measurements is provided in the relating ITU report SM.2256 [13]. Unlicensed communication in the UHF band has also a great actuality. Measurements in Italy, Spain, and Romania are presented in $[14,15]$ in order to estimate practical parameters to ensure the feasible and harmless unlicensed communication in the UHF TV bands. Special devices like wireless microphones may also utilize this band under strict regulatory control [16], that is, also increasing the importance of accurate spectrum sensing methods.

In the present paper we demonstrate mobile measurements in the DVB-T spectrum by concentrating on the occupancy statistics that can be inferred from the channel fading dynamics. We significantly extended our former paper [17] with technical details and additional measurement route; furthermore results and conclusions are amended.

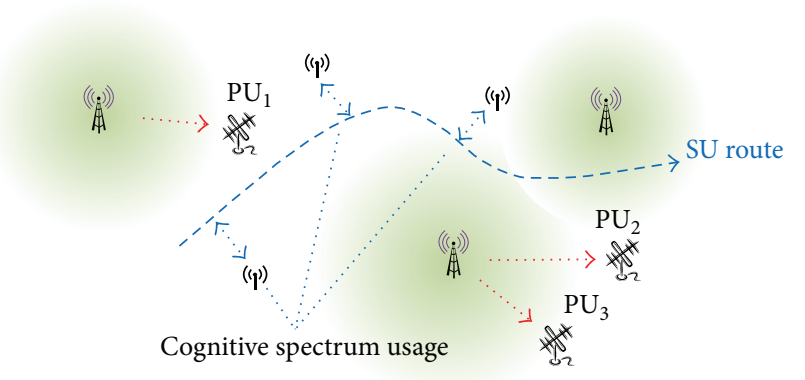

FIgURE 1: Fixed PUs and a moving SU for smart DVB-T spectrum utilization.

DVB-T users are the primary owners of the television receivers $[18,19]$. In large cities, like Budapest, where we conducted our measurements, the sufficient service requires several multiplexed channels and usually more than one transmit station. DVB-T receivers are the primary users of this spectrum and the service provider takes care of the sufficient quality of service at the whole geographical region [20]. Nevertheless, in densely built-in areas and especially in case of hilly areas the received signal level could be locally insufficient to receive the DVB-T signal properly. In this case by applying smart spectrum sensing technologies a secondary, mobile user has an opportunity to utilize this spectrum for different kind of short-distance communications, like accessing locally transmitted traffic information and carto-car communications, or for general type of data transfer. A hypothetical scenario is depicted in Figure 1.

Therefore our main goal during this survey was to investigate the frequency band of the terrestrial digital television broadcasting between 400 and $900 \mathrm{MHz}$ to have an overview of the possibilities for mobile CR applications [21]. In order to achieve this goal the appropriate measurement devices had to be selected and also designed if off-the-shelf equipment was not available. The air interface was a custom designed wide band discone antenna. For sensing the radio spectrum, a handheld spectrum analyser was applied. As the measurement campaign was planned for mobile measurements aboard a vehicle, an appropriate and safe mechanical setup was needed. The route and the speed of movement were recorded by a GPS-based navigation system.

The main target of this research was twofold: primarily received power time series was recorded in a wide DVB-T band while a vehicle was moving in city area. Secondly, by processing the measured data, first- and second-order statistics were derived allowing inferring the CR opportunities in this band.

\section{Measurement Location and Modelling}

In the time of the measurements (12/2013 and 03/2014) in Budapest three DVB-T transmitters were operating. Each of them has multiplex channels with the standard $8 \mathrm{MHz}$ bandwidth providing the sufficient receiving conditions over the whole city. It is worthy of note that in the majority of the 
TABLE 1: DVB-T transmitters in Budapest.

\begin{tabular}{|c|c|c|c|c|c|c|}
\hline \multirow[b]{2}{*}{$\mathrm{CH}$} & \multicolumn{3}{|c|}{ UHF channels $[\mathrm{MHz}]$} & \multicolumn{3}{|c|}{ Max. ERP $[\mathrm{kW} / \mathrm{dBm}]$} \\
\hline & Starting & Centre & Ending & Széchenyi Hill 1 & Hármashatár Hill 2 & $\begin{array}{ll}\text { Száva Street } 3 \\
\end{array}$ \\
\hline 38 & 606 & 610 & 614 & $100 / 80$ & $9,5 / 69,8$ & $6,2 / 67,9$ \\
\hline 55 & 742 & 746 & 750 & $39,8 / 76$ & $9,8 / 70$ & $7,1 / 68,5$ \\
\hline 58 & 766 & 770 & 774 & $100 / 80$ & $7,4 / 68,7$ & $5,6 / 67,5$ \\
\hline & Locati & /Lon./As & & $47^{\circ} 29^{\prime} / 18^{\circ} 58^{\prime} / 457 \mathrm{~m}$ & $47^{\circ} 33^{\prime} / 19^{\circ} 00 / 443 \mathrm{~m}$ & $47^{\circ} 28^{\prime} / 19^{\circ} 07^{\prime} / 120 \mathrm{~m}$ \\
\hline
\end{tabular}

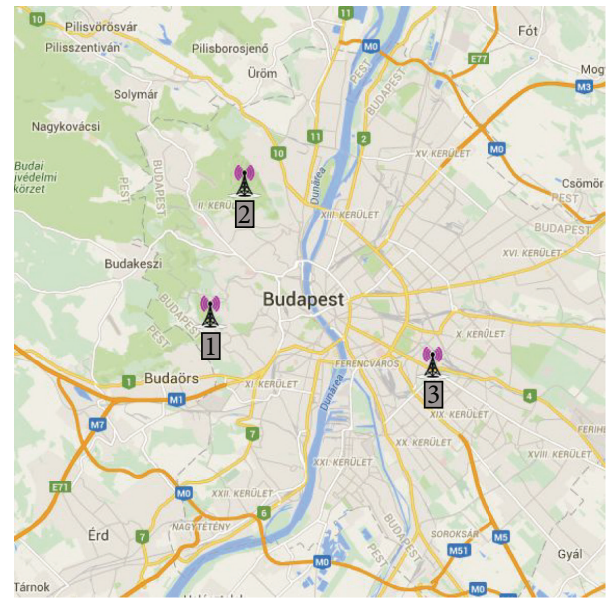

Figure 2: DVB-T transmitters in Budapest (map source: Google).

European countries the transition from analogue to digital TV broadcasting technologies was finished (see, for example, [22]), and there are only a few countries where this is still an ongoing process.

In Table 1 the main transmitter parameters can be found for Budapest.

The transmitter locations are depicted in the map shown in Figure 2, denoted with 1,2 , and 3 signs. It is worth mentioning that the left side of the city is hilly while the right side is flat; however transmitter 3 can be found on elevated location. The arrangement of the transmitters and their power radiated ensure the location-independent receiving despite the geographical variability.

For a first and rough estimation of the received signal power at the different geographical positions the OkumuraHata channel model [23] was selected to illustrate the capabilities and limitations of such calculations. This model is valid for $150-1500 \mathrm{MHz}$ frequency range; therefore it is well applicable for DVB-T. It is an empirical model suitable to calculate the path loss $L_{U}$ for different urban areas. The $h_{T}$ height of the transmit antenna and the $h_{R}$ receiver antenna height are also input parameters of the model:

$$
\begin{aligned}
L_{U}= & 69.55+26.16 \log _{10} f^{[\mathrm{MHz}]}-13.82 \log _{10} h_{T}-C_{H} \\
& +\left[44.9-6.55 \log _{10} h_{T}\right] \log _{10} D^{[\mathrm{km}]} .
\end{aligned}
$$

$C_{H}$ is the antenna height coefficient and it is for small and medium cities:

$$
\begin{aligned}
C_{H}= & 0.8+\left(1.1 \log _{10} f^{[\mathrm{MHz}]}-0.7\right) h_{R} \\
& -1.56 \log _{10} f^{[\mathrm{MHz}]},
\end{aligned}
$$

and for big cities,

$$
\begin{aligned}
& C_{H} \\
& = \begin{cases}8.29 \log _{10}\left(1.54 h_{R}\right)^{2}-1.1, & 150 \leq f^{[\mathrm{MHz}]} \leq 200 \\
3.2 \log _{10}\left(11.75 h_{R}\right)^{2}-4.97, & 200 \leq f^{[\mathrm{MHz}]} \leq 1500 .\end{cases}
\end{aligned}
$$

The model has limitations in range $(1-20 \mathrm{~km})$ and transmitter antenna height (30-200 m). By taking into account that the sea level height of the city (river floor) is $90 \mathrm{~m}$, the model could be applied for a rough estimation of the received signal level. In the following this calculation is presented, where we considered big city model coefficients and provide received signal power map for each transmitter frequency.

To calculate with the Okumura-Hata model, we positioned three transmitters into a hypothetical square of $20 *$ $20 \mathrm{~km}$; the origin of this area was $N 47^{\circ} 25^{\prime}$ and $E 18^{\circ} 54^{\prime}$. The positions of the transmitters are representing their real geographical places relatively to this origin. The gain of the transmitter antennas was selected uniformly $15 \mathrm{~dB}$ and the receiver location was $3 \mathrm{~m}$, respectively. The result is depicted in Figure 3, where the transmitters are numbered according to Table 1.

The modelled signal level in the rectangular area visualizes the received power at different locations produced by the DVB-T transmitters. Besides the Okumura-Hata model, the Walfisch-Ikegami and the Lee models are compared and tested for different geographical areas in [24]. In this paper, the goal of the modelling was to get a quantitative overview of the received signal power field and therefore we selected for our calculations one of the best known models.

Nevertheless, the effect of the local variation of the environment, for example, shadowing of buildings, reflections, and local interferences, is not visible in Figure 3. In order to generate a more accurate power map, a detailed geolocation map would be required, containing an exact database of the object positions and dimensions across the city, but such a database was not available for the authors.

The lack of the fine structure and the variation of the signal level on a specific route require a different approach. The description of this method and its conclusions is the following subject of this paper. 


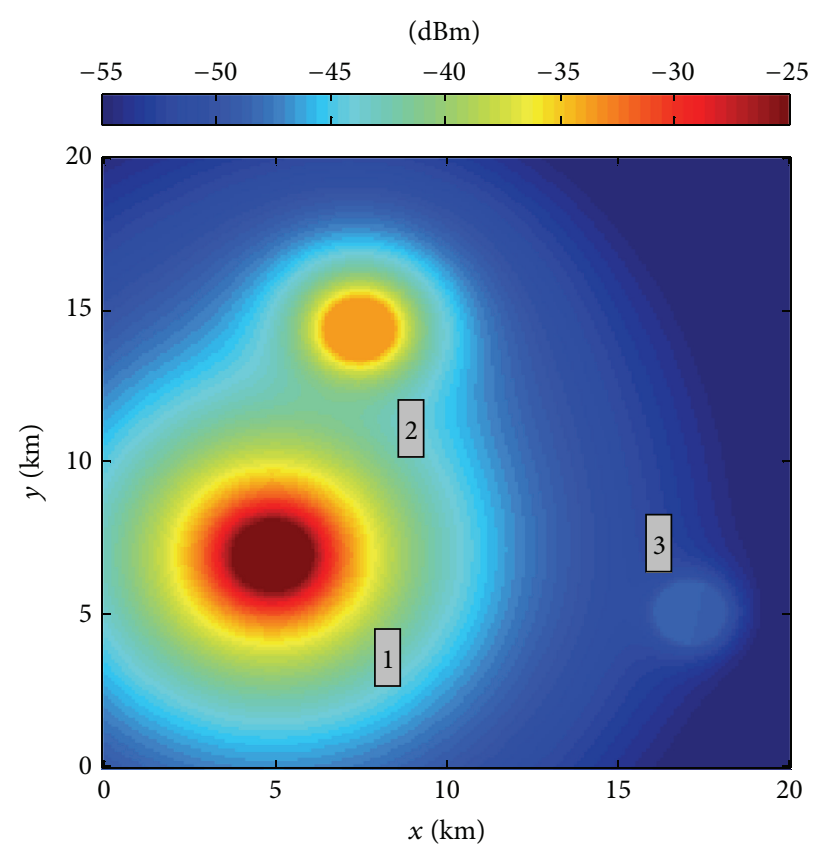

(a)

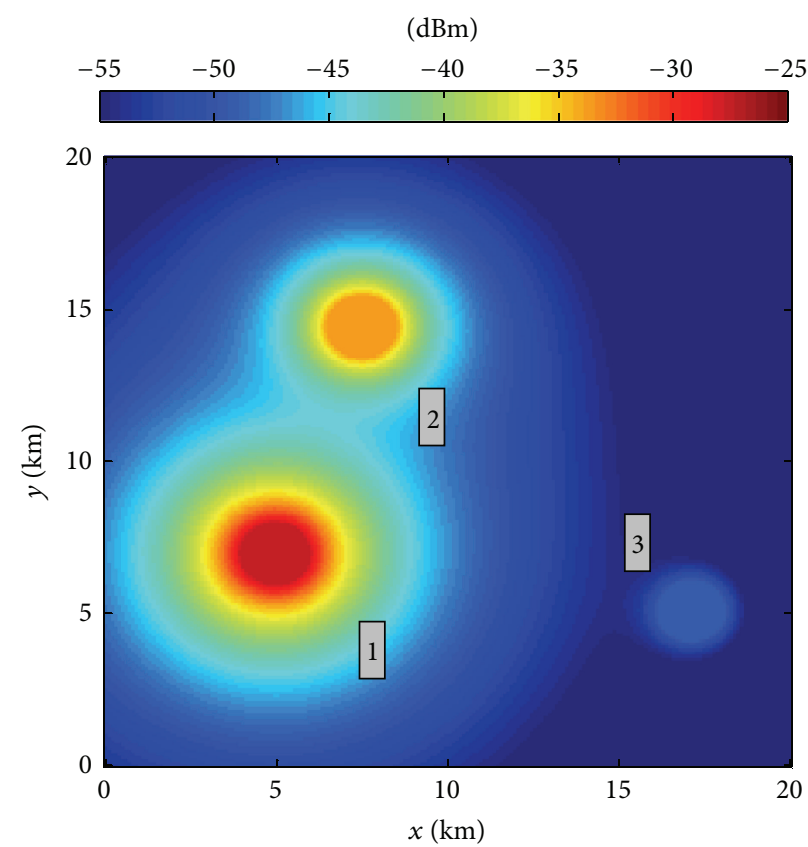

(b)

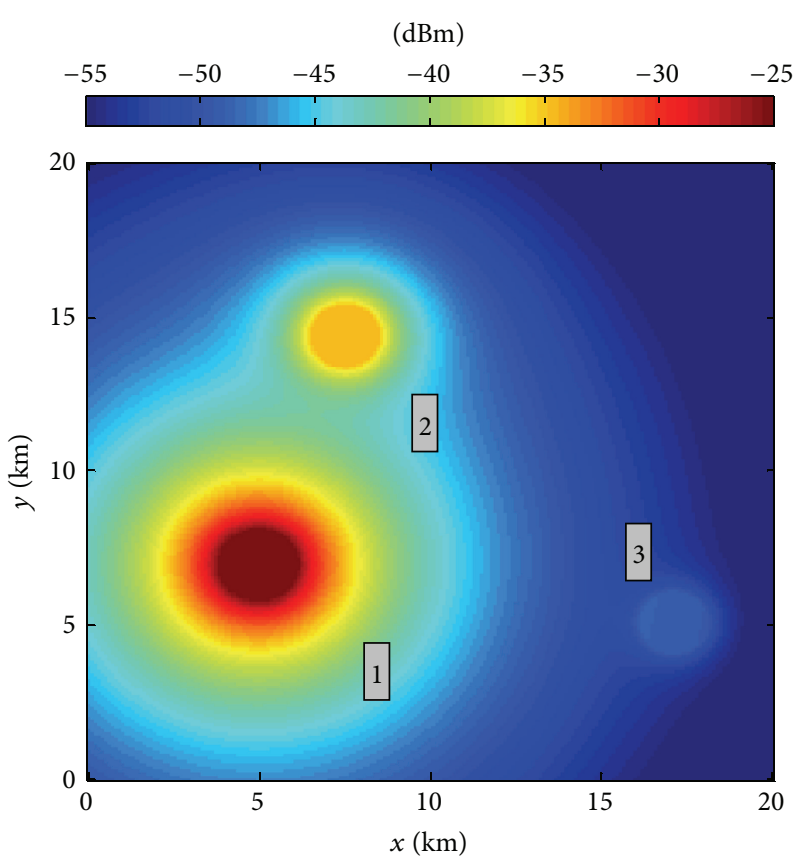

(c)

Figure 3: DVB-T signal power at $610 \mathrm{MHz}$ (a), $746 \mathrm{MHz}$ (b), and $770 \mathrm{MHz}$ (c), calculated with Okumura-Hata model.

\section{Receiver Antenna Design for Spectrum Sensing}

Our goal was to build an all-purpose system that is capable of wide range spectral observations between 0.4 and $3 \mathrm{GHz}$. In [25] for a similar measurement a commercially available 25-1300 MHz antenna was proposed, but for our purposes we selected a customized antenna that has a broader bandwidth. Therefore a special wideband antenna was designed [26] at our department whose omnidirectional characteristic was one of the most important requests (see Figure 4).

The requirements are well fulfilled by a discone antenna that consists of a flat disc on the top of a conical part. Within this structure, the wideband operation is mainly determined by the conical structure. The drawing and final dimensions of the antenna can be found in Figure 4. Before antenna fabrication, computer simulations were done in order to prove the performance and check the main parameters. 


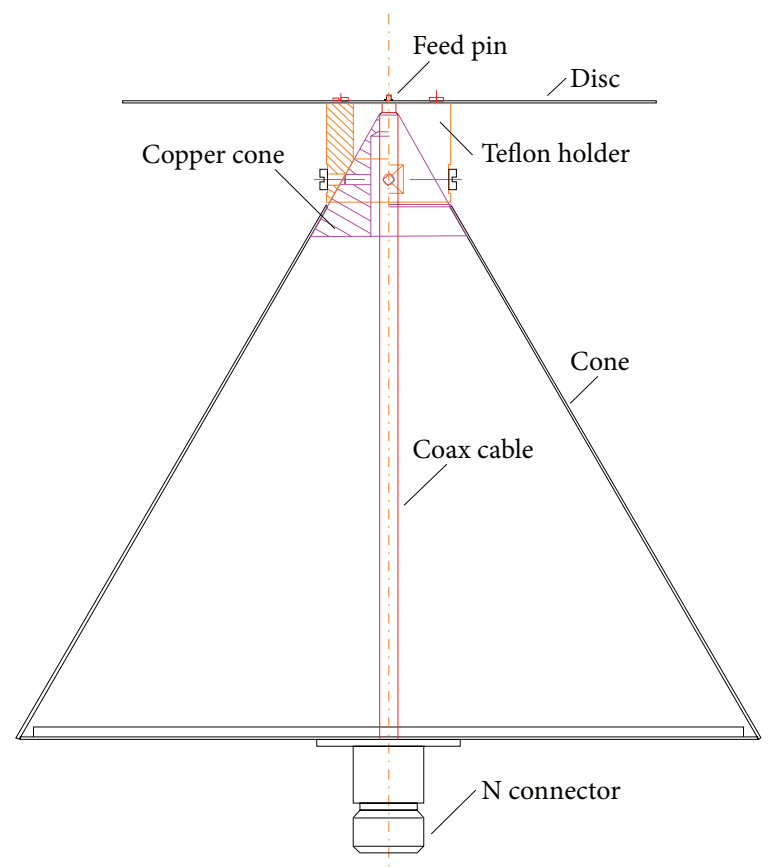

\begin{tabular}{lc}
\hline Main antenna dimensions: & \\
\hline Cone max. diameter: & $210 \mathrm{~mm}$ \\
Cone angle: & $60^{\circ}$ \\
Disc diameter: & $150 \mathrm{~mm}$ \\
Total height (w/o connector): & $180 \mathrm{~mm}$ \\
\hline
\end{tabular}

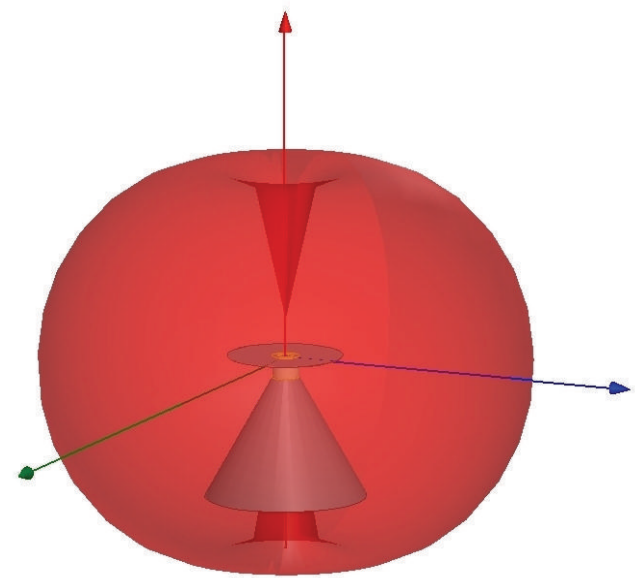

Figure 4: Antenna dimensions and simulated characteristics at $746 \mathrm{MHz}$.
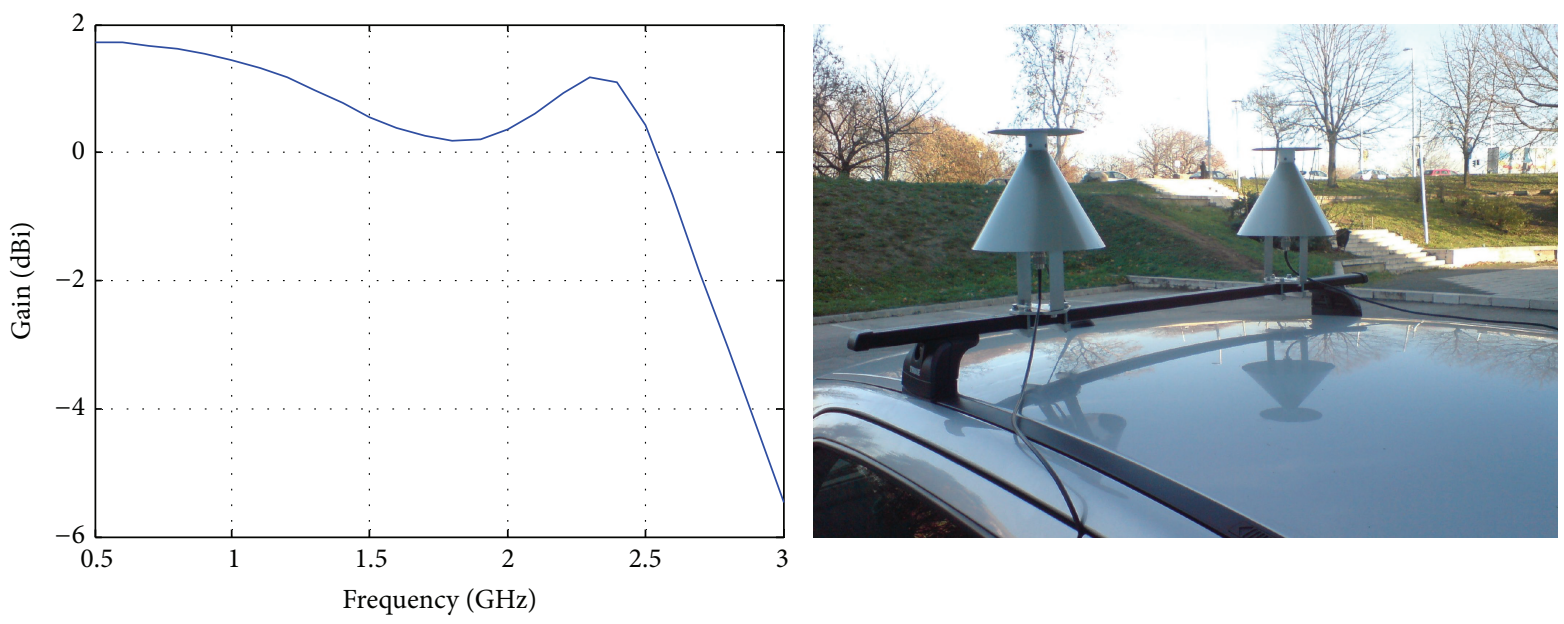

FIGURE 5: Simulated antenna gain and a two-channel measurement setup.

The simulated antenna of a characteristic at $746 \mathrm{MHz}$ is depicted in Figure 4 while variation of the gain with frequency is depicted in Figure 5. The latter figure also illustrates a two-antenna system assembled on the top of a car, ready for mobile measurements. The gain of the antenna is slightly varying with the frequency and according to the simulation it is nearly $2 \mathrm{~dB}$ in the investigated DVB-T frequency band.

\section{Mobile Sensing of the DVB-T Spectrum}

Spectrum sensing is a secondary user's task when his operation is based on CR technology. SUs should discover usually a wide frequency band before they can utilize any spectra. This is an indispensable process, because the main owners of the spectrum, the Pus, cannot be disturbed or restricted in their operation. The air interface of this kind of sensing is usually a wideband and omnidirectional antenna. Wideband sensing requires intelligent, programmable received signal detection that allows scanning the selected frequency range and performing fast energy detection at the single frequencies. During our work we applied professional measurement devices for similar purposes in order to explore the DVB$\mathrm{T}$ spectrum in a larger geographical area. The measurement could be a base to qualify the DVB-T spectrum for mobile cognitive radio applications. 


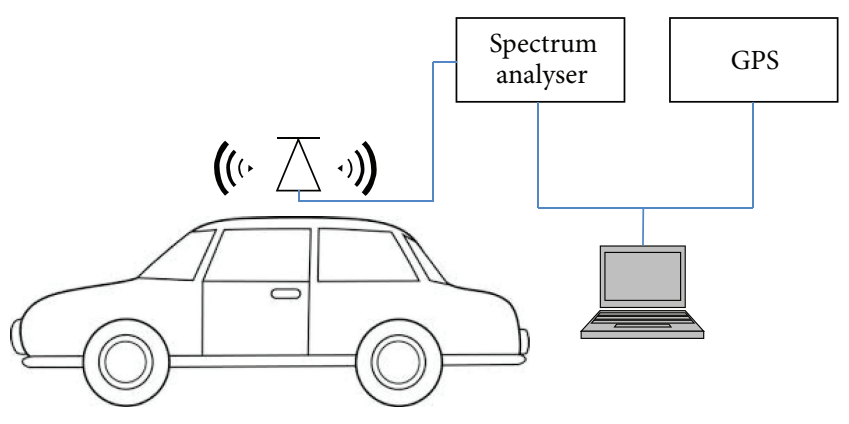

Figure 6: Mobile spectrum measurement setup.

This section provides the detailed measurement setup for our experiments, and then time series and different statistics will be presented.

In Section 2 we have seen that the modelled received signal map, especially in absence of a geolocation database of terrestrial objects, cannot provide sufficient information about the local variability of the signal level. In order to investigate the exact time series of the DVB-T signal power aboard a moving vehicle a measurement with locationtagging was designed and conducted. As spectrum sensing device, a type of Agilent N9340B Handheld RF spectrum analyser was utilized. For our research purposes, the flexibility and precision of such a measurement tool were an obvious solution. The investigated frequency band is supported by the applied device [27], and its built-in memory was able to store the measurement data through the whole route.

The measurement setup for the mobile system is depicted in Figure 6 and it has the following main blocks:

(i) A car equipped with a single discone antenna (see Section 3).

(ii) A GPS device to record the route and the moving speed (Mitac P560 PDA).

(iii) A portable spectrum analyser [27] with data storage capability (Agilent N9340B).

(iv) A notebook to archive measurement files.

To have a first look of the measured data, a waterfall diagram is a good opportunity (see Figure 8), depicting the received signal power in the complete frequency band for the total measurement period.

In order to survey the DVB-T frequency band during movement, two measurements were conducted in the city area of Budapest. The routes are depicted in Figure 7, also denoting their length and duration.

In order to cover the whole frequency band of the TV transmitters, the following spectrum analyser settings were applied:

(i) Starting frequency: $590 \mathrm{MHz}$.

(ii) Stop frequency: $800 \mathrm{MHz}$.

(iii) Span: $210 \mathrm{MHz}$.

(iv) Span time: $2 \mathrm{sec}$.

(v) Attenuation: $10 \mathrm{~dB}$. (vi) Bandwidth: $100 \mathrm{kHz}$.

(vii) Reference noise power: $-109 \mathrm{dBm}$.

$10 \mathrm{~dB}$ attenuation was required to keep the measured signal level within the analyser measurement range. The 590$800 \mathrm{MHz}$ frequency band was sensed with $10 / 22 \mathrm{MHz}$ steps; thus, for example, for a $8 \mathrm{MHz}$ DVB-T channel, 17.6 samples were collected. The spectrum analyser stores the measured received power in floating point data type with two decimal places. The antenna was connected with RG-58 type cable of $3 \mathrm{~m}$ length; therefore the cable attenuation was $0.9 \mathrm{~dB}$.

TV transmitters 1 and 3 were closed by the routes (their places are marked on the maps). The speed of the car was slightly varying, but it was kept during the route as stable as possible.

After processing the measurements, the spectrogram and the time series of the received power for three TV channels are providing the first overview of the investigated spectrum. In the spectrogram and even more clearly in the received power time series, the strong variations of the signal levels are well observable (Figures 8-9).

The results are indicating that the conditions of proper DVB-T receiving do not always exist. As the measurement was performed in densely built-in city area and we considered the movement of the car, different type of channel impairments may arise. The shadowing, interference, and multipath propagation could decrease the quality of service. However the Okumura-Hata propagation model is a wellknown tool to calculate the received signal level in built-in areas [28, 29]; this is a general model and cannot substitute the real measurements like the present one, allowing deriving a more accurate characterization of the mobile propagation channel. For proper DVB-T, receiving primary users require $50 \mathrm{~dB} \mu \mathrm{V}$ signal level, or considering a $50 \Omega$ termination from (4), this level is $-57 \mathrm{dBm}[30]$ :

$$
\begin{aligned}
\mathrm{RP}_{\text {min }}{ }^{\mathrm{dBm}} & =\mathrm{RP}_{\text {min }}{ }^{\mathrm{dB} \mu \mathrm{V}}-90-20 \log \left(\sqrt{Z^{\Omega}}\right) \\
& =-57 \mathrm{dBm} .
\end{aligned}
$$

More detailed discussion about the planning of DVB-T service area and the minimum field strength requirements can be found in [31].

We will apply this threshold as an opportunity indicator for secondary channel usage. On the other hand, it should be also considered that, in order to minimise the harmful interference caused by the cognitive secondary user devices, the TV signal sensing margin should be much lower than that of TV receivers required for high quality receiving [32]. The hidden node problem, when a primary user with good receiving conditions is interfered by a secondary transmitting device [33], is one of the reasons that cognitive devices are usually operating with lower sensing margin. Nevertheless, this kind of problem is beyond the scope of this paper; the abovementioned $-57 \mathrm{dBm}$ will be for us the measure of the local DVB-T signal quality. As the goal of this paper is a survey of the TVWS, the investigation of some statistical properties of the received signal time series will lead to the estimation of the secondary channel utilization 


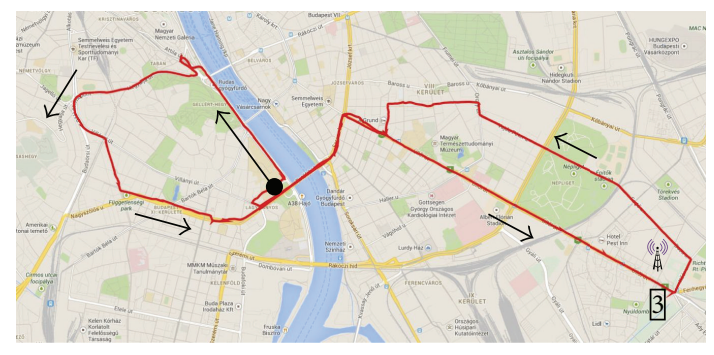

(a)

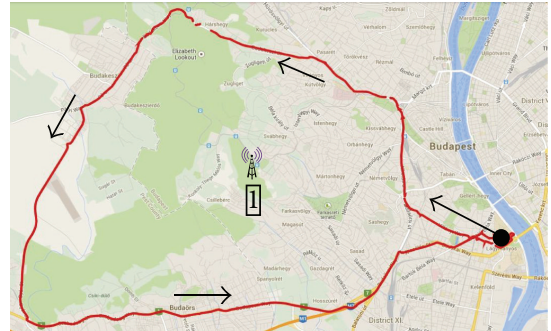

(b)

Figure 7: (a) Route 1 (22.9 km, 58 min, 12/2013). (b) Route 2 (34.9 km, 58.8 min, 03/2014) (map sources: Google).

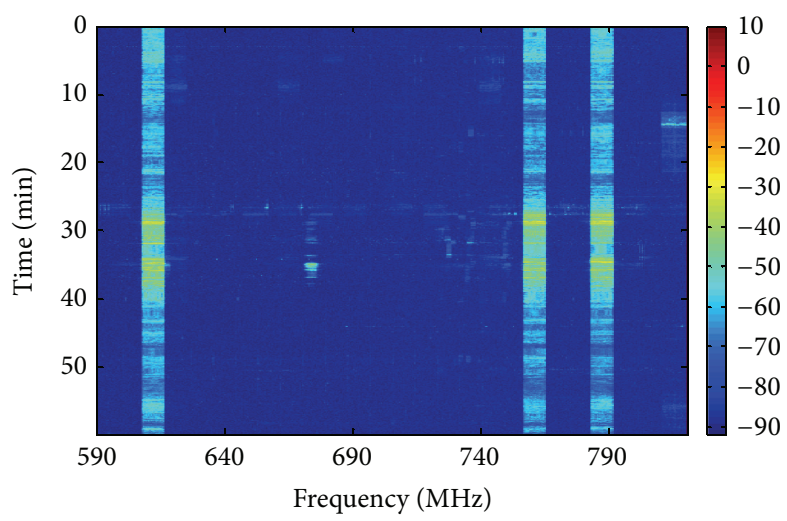

opportunities. We emphasize that for an operational cognitive radio application a lower sensing margin should be required. Furthermore, especially to avoid the interference additional techniques would be also desirable, for example, pilot detection, cyclostationary feature detection, or cyclic prefix and autocorrelation detection [32].

To find the probability of the minimal received signal level, the Cumulative Distribution Function (CDF) of the attenuation could help. To estimate a realistic receiving condition, an increased antenna gain should be applied, because the discone antenna is only an experimental device and it does not represent correctly the antenna of a standard DVB-T receiver. The applied discone antenna has $\sim 2 \mathrm{~dB}$ gain; nevertheless for real DVB-T receiving an antenna with 10$12 \mathrm{~dB}$ gain is recommended [34] and usually applied by PUs.

The CDF of the received power indicates the probability that the signal level is less than or equal to a certain value, as it is depicted in Figure 10 for the two different routes. If we take
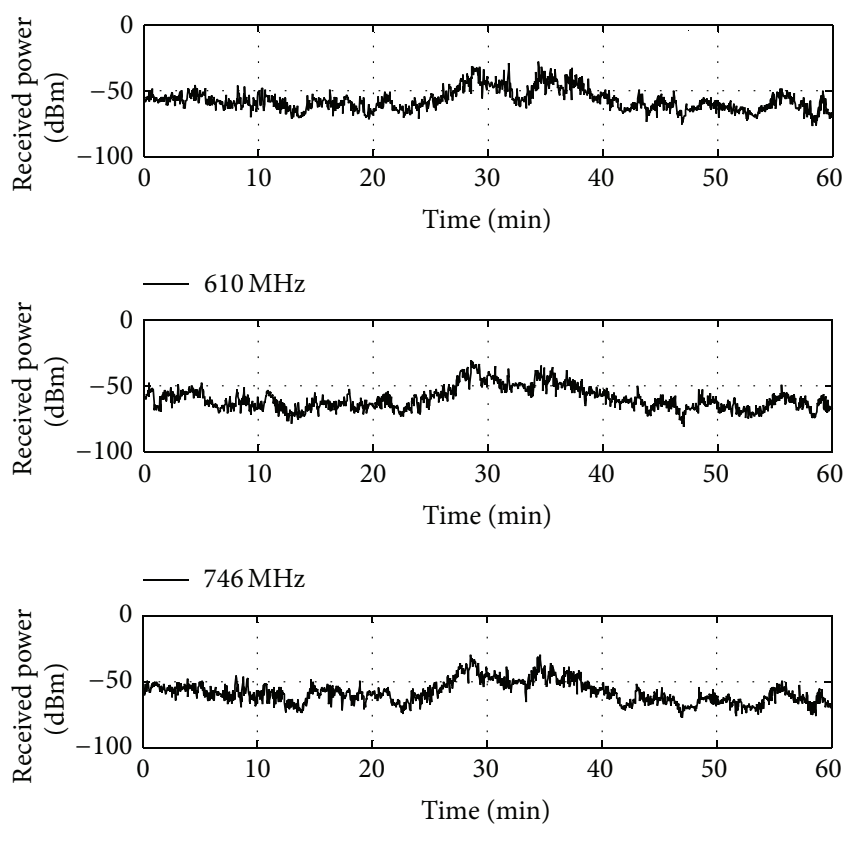

$-770 \mathrm{MHz}$

FIGURE 8: Spectrogram and received power time series at TV channel centre frequencies (Route 1).

into account that a standard PU has a receiving antenna with an additional $10 \mathrm{~dB}$ gain compared to the discone antenna in the measurement, according to (4) the probability values at $-57-10=-67 \mathrm{~dB}$ are representing the thresholds of the improper receiving conditions.

One can see that the probability of insufficient DVB$\mathrm{T}$ signal level is relatively high; in Figure 10 these values are indicated for each channel. Contrarily, in case of this condition the spectrum could be utilized by the secondary users for their own purposes by applying CR technologies.

Another aspect of the estimation of the channel impairment is the fade duration statistics [35]. While the attenuation statistics inform us about the probability that the fading depth exceeds a specified level, the length of the individual fade events and thus the possible outage periods could be determined only from the fade duration distribution. The duration of fades can be calculated from the attenuation time series; therefore the received power time series (see Figures 8 

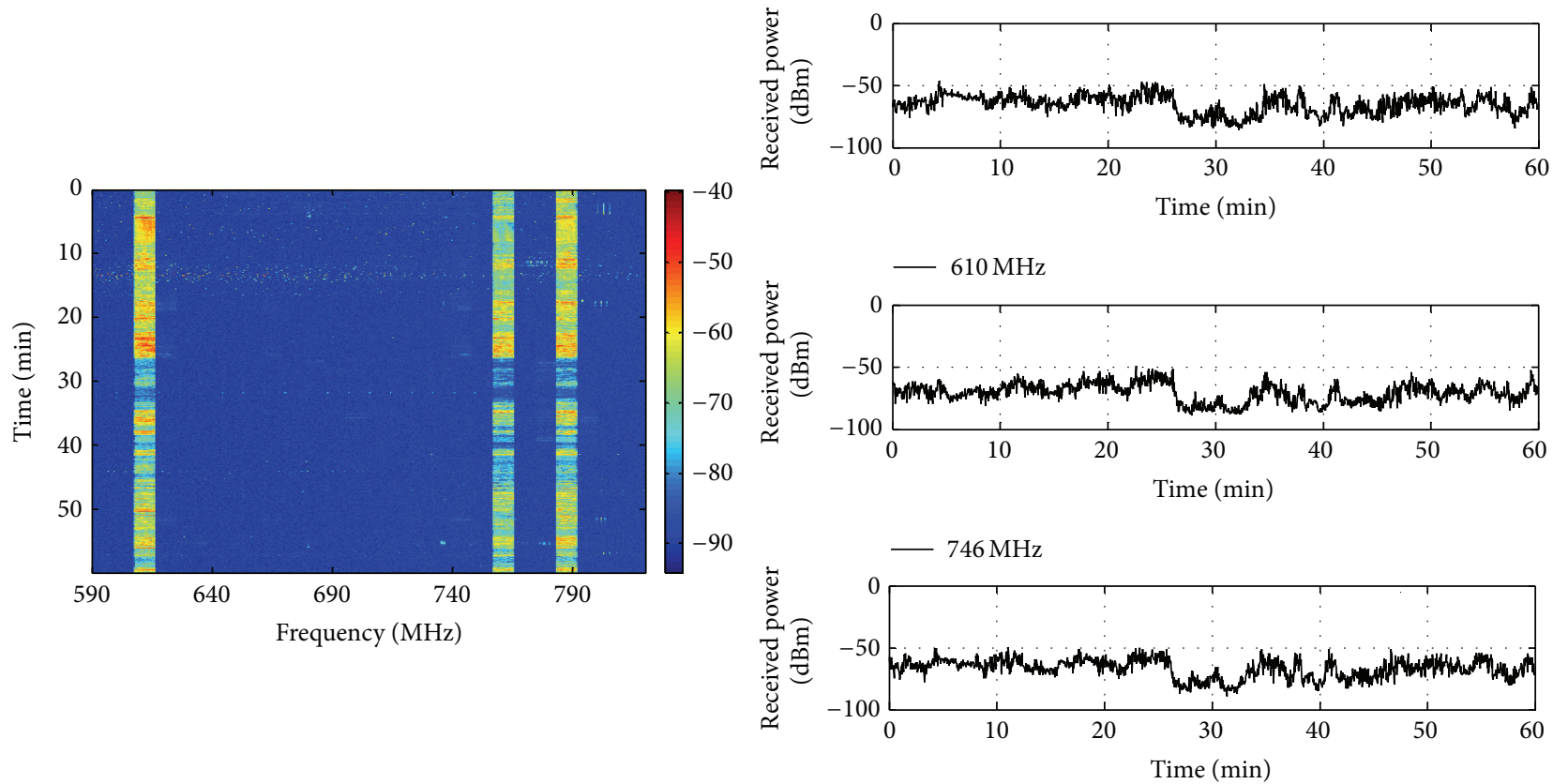

$-770 \mathrm{MHz}$

FIGURE 9: Spectrogram and received power time series at TV channel centre frequencies (Route 2).

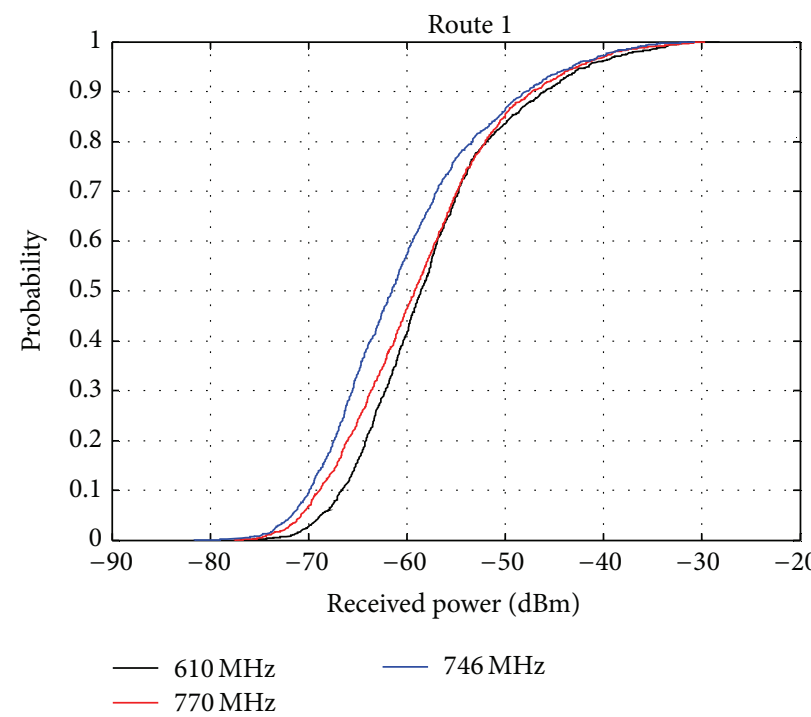

Improper receiving conditions probabilities:

At $610 \mathrm{MHz}: 0.08$

At $746 \mathrm{MHz}: 0.22$

At $770 \mathrm{MHz}: 0.15$

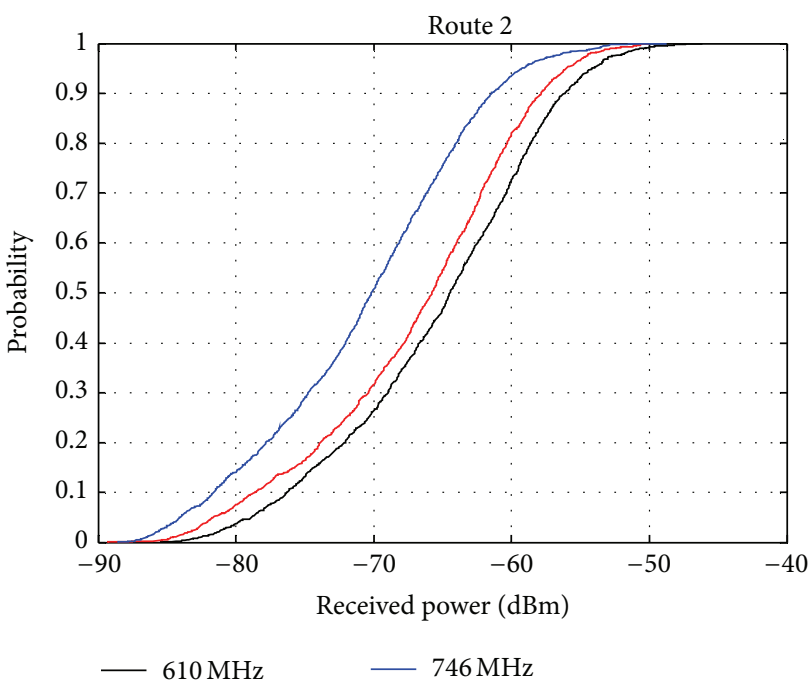

$-610 \mathrm{MHz}$

Improper receiving conditions probabilities:

At $610 \mathrm{MHz}: 0.38$

At $746 \mathrm{MHz}: 0.66$

At $770 \mathrm{MHz}: 0.44$

FIGURE 10: CDF of received power and probabilities of improper receiving conditions.

and 9) should be converted. For this conversion, the highest measured received power value in the DVB-T channel was considered as a reference (zero attenuation) level.

Besides the fade duration, in cognitive radio applications the level crossing rate as another dynamics aspect of the channel is studied in [36] for Rayleigh and Rician fast fading channels. The effect of imperfections in the radio environment map (REM) information on the performance of cognitive radio (CR) systems was investigated in [37]. In opportunistic channel allocation algorithms [38] the duration of fade event may play an important role. Therefore in our paper we propose fade duration statistics as a tool for opportunity length estimation.

Figure 11 indicates the probability of fade durations at $15 \mathrm{~dB}$ and $20 \mathrm{~dB}$ attenuation levels for 10 and 60 seconds, respectively. We proved with our measurements and with the 

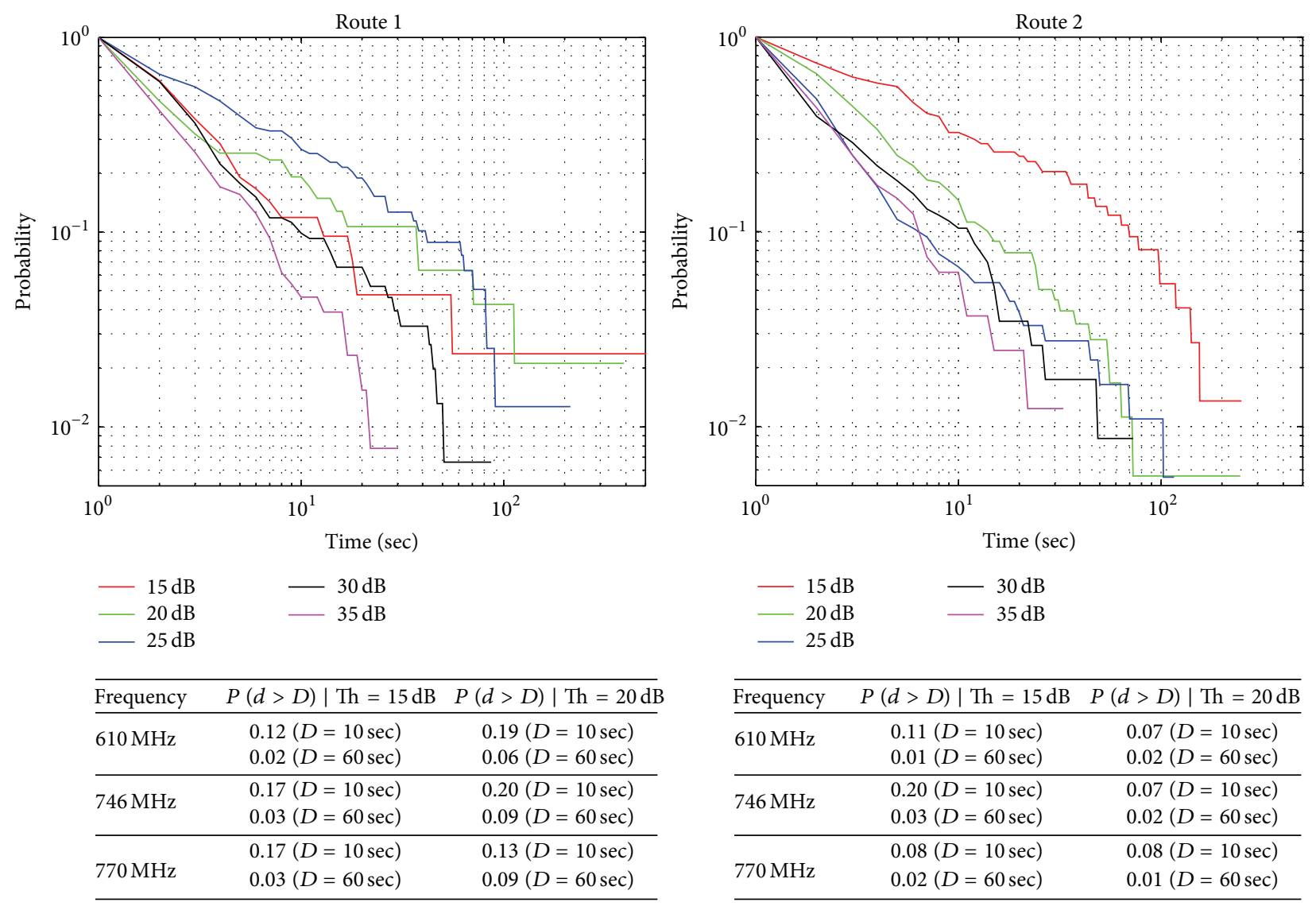

FIGURE 11: Fade duration distribution of the $610 \mathrm{MHz}$ channel and probabilities of 10 and 60 sec fade events (all channels).

relating fade duration statistics that aboard a moving device in city area the DVB-T spectrum can be used for secondary purposes even for several seconds or for a minute duration. Calculating with one-hour travelling, the opportunity for secondary channel usage during this journey is several minutes in $10 \mathrm{~s}$ quanta and even some complete minutes. These are significant values that should be taken into account if secondary channel utilization of the DVB-T spectra is planned.

For the calculations above we applied $-57 \mathrm{dBm}$ threshold, that is, according to the literature, the signal level required for the error-free DVB-T reception. Our proposal is that the secondary usage of the spectrum is a reality when the service quality is insufficient for the primary users. Contrarily, for cognitive radio applications the protection of primary user's service quality is a key issue. The appearance of secondary users may cause significant interference in the TVWS; therefore an advanced spectrum sensing technique is essential. A study about this emerging technology [39] discusses that the sensing threshold is $-112.8 \mathrm{dBm}$ for $8 \mathrm{MHz}$ wide channels, showing that high quality sensing technique is inevitable in a real CR application.

\section{Conclusions}

In this paper we presented wideband, mobile DVB-T spectrum measurements to study the variation of the received signal power in the TV channel frequencies. Our suggestion is that for cognitive radio applications the same frequency band is applicable if the service quality for the PUs is insufficient. It may happen in densely built-in city areas that, due to shadowing, reflections, or interference, the DVB-T signal quality is improper for primary usage. This fact has been proved by the measurements. In this case of short-distance communications, for example, for car-to-car data transfer or access local traffic information databases or even for selfdriving vehicles, the DVB-T spectrum could be utilized. In the paper the antenna design for spectrum detection, the applied spectrum sensing hardware, measurement methods, and their statistics were shown. After the evaluation of the results it was proven that for mobile CR users it is possible to utilize the DVB-T band with intelligent devices for secondary purposes, even without decreasing the QoS of the primary users.

\section{Competing Interests}

The authors declare that they have no competing interests.

\section{References}

[1] I. F. Akyildiz, W.-Y. Lee, M. C. Vuran, and S. Mohanty, "NeXt generation/dynamic spectrum access/cognitive radio wireless networks: a survey," Computer Networks, vol. 50, no. 13, pp. 2127-2159, 2006. 
[2] O. Simeone, J. Gambini, Y. Bar-Ness, and U. Spagnolini, "Cooperation and cognitive radio," in Proceedings of the IEEE International Conference on Communications (ICC '07), pp. 6511-6515, Glasgow, UK, June 2007.

[3] E. Axell, G. Leus, and E. G. Larsson, "Overview of spectrum sensing for cognitive radio," in Proceedings of the 2nd International Workshop on Cognitive Information Processing (CIP '10), pp. 322-327, Elba, Italy, June 2010.

[4] A. Garhwal and P. P. Bhattacharya, "A survey on spectrum sensing techniques in cognitive radio," International Journal of Computer Science and Communication Networks, vol. 1, no. 2, pp. 196-206, 2011.

[5] Q. Zhao and B. M. Sadler, "A survey of dynamic spectrum access," IEEE Signal Processing Magazine, vol. 24, no. 3, pp. 7989, 2007.

[6] D. Das and S. Das, "A survey on spectrum occupancy measurement for cognitive radio," Wireless Personal Communications, vol. 85, no. 4, pp. 2581-2598, 2015.

[7] M. A. McHenry, P. A. Tenhula, D. McCloskey, D. A. Roberson, and C. S. Hood, "Chicago spectrum occupancy measurements \& analysis and a long-term studies proposal," in Proceedings of the 1st International Workshop on Technology and Policy for Accessing Spectrum (TAPAS '06), article 1, ACM, Boston, Mass, USA, 2006.

[8] M. Mehdawi, N. Riley, M. Ammar, and M. Zolfaghari, "Comparing historical and current spectrum occupancy measurements in the context of cognitive radio," in Proceedings of the 20th Telecommunications Forum (TELFOR '12), pp. 623-626, Belgrade, Serbia, November 2012.

[9] A. Kliks, P. Kryszkiewicz, K. Cichoń, A. Umbert, J. PerezRomero, and F. Casadevall, "DVB-T channels measurements for the deployment of outdoor REM databases," Journal of Telecommunications and Information Technology, no. 3, pp. 4252, 2014.

[10] S. Jayavalan, H. Hafizal, N. M. Aripin et al., "Measurements and analysis of spectrum occupancy in the cellular and TV bands," Lecture Notes on Software Engineering, vol. 2, no. 2, pp. 133-138, 2014.

[11] A. Kliks, P. Kryszkiewicz, J. Perez-Romero, A. Umbert, and F. Casadevall, "Spectrum occupancy in big cities-comparative study. Measurement campaigns in Barcelona and Poznan," in Proceedings of the 10th International Symposium on Wireless Communication Systems (ISWCS '13), pp. 1-5, Ilmenau, Germany, August 2013.

[12] P. I. Lazaridis, S. Kasampalis, Z. D. Zaharis et al., "UHF TV band spectrum and field-strength measurements before and after analogue switch-off," in Proceedings of the 2014 th International Conference on Wireless Communications, Vehicular Technology, Information Theory and Aerospace and Electronic Systems (VITAE '14), pp. 1-5, Aalborg, Denmark, May 2014.

[13] ITU-R, "Spectrum occupancy measurements and evaluation," Report ITU-R SM.2256, 2012.

[14] P. Angueira, M. Fadda, J. Morgade, M. Murroni, and V. Popescu, "Field measurements for practical unlicensed communication in the UHF band," Telecommunication Systems, vol. 61, no. 3, pp. 443-449, 2016.

[15] M. Fadda, V. Popescu, M. Murroni, P. Angueira, and J. Morgade, "On the feasibility of unlicensed communications in the TV white space: field measurements in the UHF band," International Journal of Digital Multimedia Broadcasting, vol. 2015, Article ID 319387, 8 pages, 2015.
[16] Federal Communications Commission, "Spectrum access for wireless microphone operations," FCC Record FCC-14-145, Federal Communications Commission, 2014.

[17] L. Csurgai-Horváth, I. Rieger, and J. Kertesz, "Mobile access of the DVB-T channel and the opportunity for cognitive spectrum utilization," in Proceedings of the 17th International Conference on Transparent Optical Networks (ICTON '15), pp. 1-4, Budapest, Hungary, July 2015.

[18] W. Van den Broeck and J. Pierson, Digital Television in Europe, VUBpress, Brussels, Belgium, 2008.

[19] U. Reimers, DVB: The Family of International Standards for Digital Video Broadcasting, Springer, Berlin, Germany, 2004.

[20] D. Noguet, R. Datta, P. H. Lehne, M. Gautier, and G. Fettweis, "TVWS regulation and QoSMOS requirements," in Proceedings of the 2nd International Conference on Wireless Communication, Vehicular Technology, Information Theory and Aerospace \& Electronic Systems Technology (Wireless VITAE '11), pp. 1-5, Chennai, India, February 2011.

[21] B. Wild and K. Ramchandran, "Detecting primary receivers for cognitive radio applications," in Proceedings of the 1st IEEE International Symposium on New Frontiers in Dynamic Spectrum Access Networks (DySPAN '05), pp. 124-130, IEEE, Baltimore, Md, USA, November 2005.

[22] R. A. Saeed and S. J. Shellhammer, Eds., TV White Space Spectrum Technologies: Regulations, Standards, and Applications, CRC Press, New York, NY, USA, 2012.

[23] M. Hata, "Empirical formula for propagation loss in land mobile radio services," IEEE Transactions on Vehicular Technology, vol. 29, no. 3, pp. 317-325, 1980.

[24] P. M. Ghosh, Md. A. Hossain, A. F. M. Zainul Abadin, and K. K. Karmakar, "Comparison among different large scale path loss models for high sites in urban, suburban and rural areas," International Journal of Soft Computing and Engineering, vol. 2, no. 2, 2012.

[25] A. Marţian, C. Vlădeanu, I. Marcu, and I. Marghescu, "Evaluation of spectrum occupancy in an urban environment in a cognitive radio context," International Journal on Advances in Telecommunications, vol. 3, no. 3-4, 2010.

[26] K.-H. Kim, J.-U. Kim, and S.-O. Park, "An ultrawide-band double discone antenna with the tapered cylindrical wires," IEEE Transactions on Antennas and Propagation, vol. 53, no. 10, pp. 3403-3406, 2005.

[27] Agilent N9340B Handheld RF Spectrum Analyzer (HSA), 3 $\mathrm{GHz}$ User Manual.

[28] ITU, "Prediction methods for the terrestrial land mobile service in the VHF and UHF bands," ITU-R Recommendation P. 529-2, ITU, Geneva, Switzerland, 1995.

[29] A. Medeisis and A. Kajackas, "On the use of the universal Okumura-Hata propagation prediction model in rural areas," in Proceedings of the IEEE 51st Vehicular Technology Conference Proceedings, vol. 3, pp. 1815-1818, Tokyo, Japan, May 2000.

[30] ROVER Laboratories SpA, “Understanding Digital TV," 2013, http://www.roverinstruments.com/.

[31] E. P. J. Tozer, Broadcast Engineer's Reference Book, Taylor \& Francis, London, UK, 2012.

[32] M. Nekovee, "A survey of cognitive radio access to TV white spaces," International Journal of Digital Multimedia Broadcasting, vol. 2010, Article ID 236568, 11 pages, 2010.

[33] Ofcom, "Statement on Cognitive Access to Interleaved Spectrum," July 2009.

[34] ITU, "DVB-T coverage measurements and verification of planning criteria," ITU-R Recommendation SM.1875-2, ITU, 2014. 
[35] ITU-R Rec. P.1623-1, Prediction method of fade dynamics on Earth-space paths, 2005.

[36] M. F. Hanif and P. J. Smith, "Level crossing rates of interference in cognitive radio networks," IEEE Transactions on Wireless Communications, vol. 9, no. 4, pp. 1283-1287, 2010.

[37] M. F. Hanif, P. J. Smith, and M. Shafi, "Performance of cognitive radio systems with imperfect radio environment map information," in Proceedings of the Australian Communications Theory Workshop (AusCTW '09), pp. 61-66, IEEE, Sydney, Australia, February 2009.

[38] H. Shatila, M. Khedr, and J. H. Reed, “Opportunistic channel allocation decision making in cognitive radio communications," International Journal of Communication Systems, vol. 27, no. 2, pp. 216-232, 2014.

[39] C. Kocks, A. Viessmann, P. Jung, L. Chen, Q. Jing, and R. Q. Hu, "On spectrum sensing for TV white space in China," Journal of Computer Networks and Communications, vol. 2012, Article ID 837495, 8 pages, 2012. 

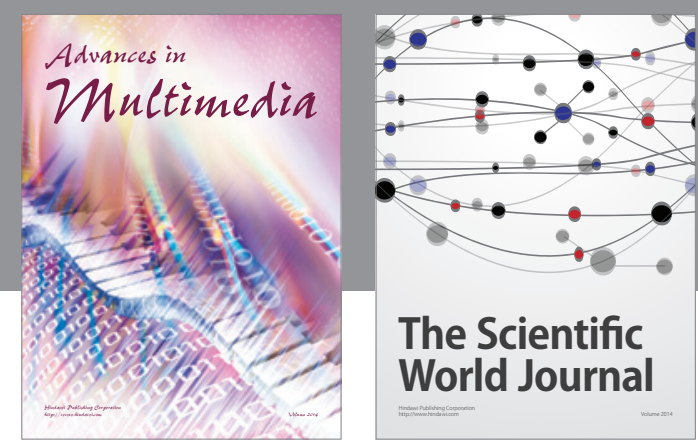

The Scientific World Journal
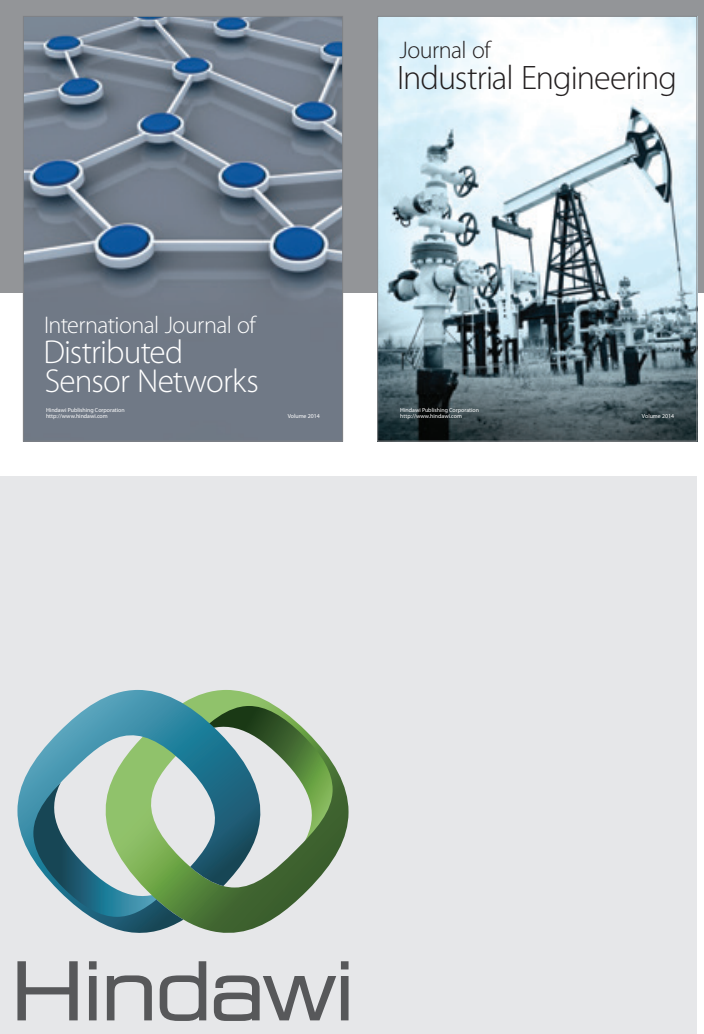

Submit your manuscripts at

http://www.hindawi.com

\section{Computer Networks} and Communications
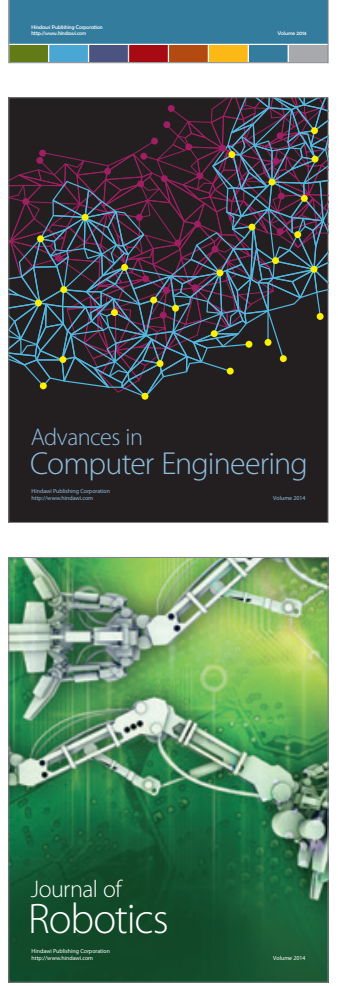
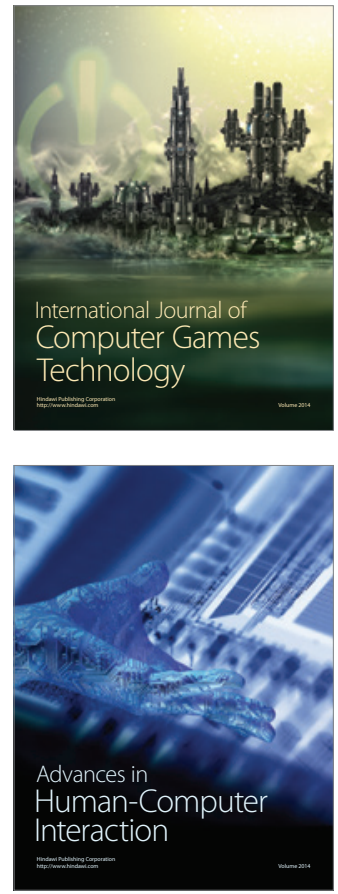
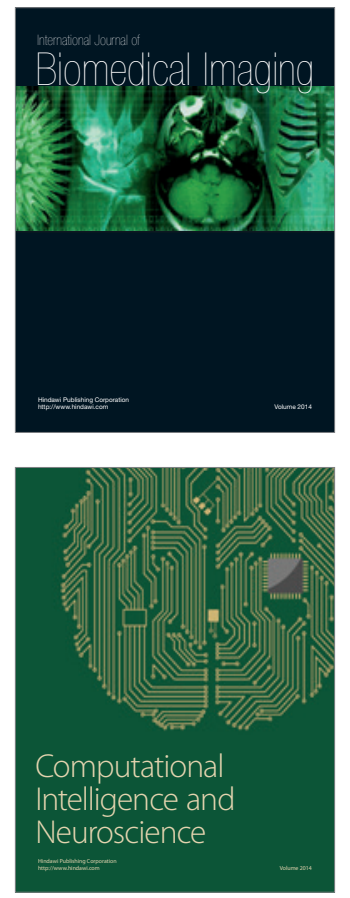
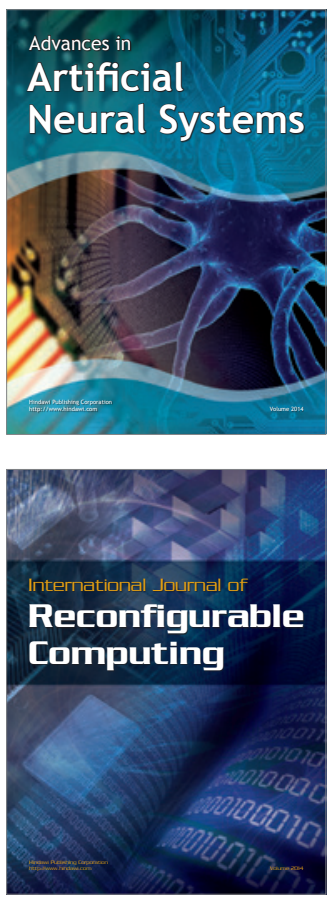
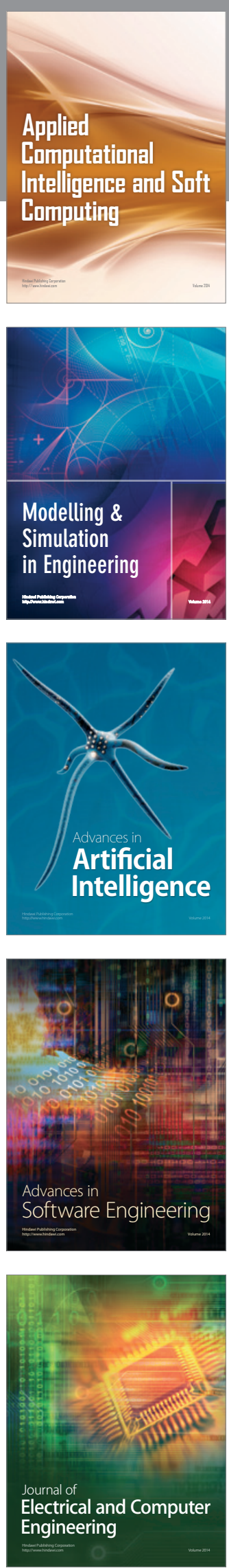